\title{
SCIENTIFIC REPORTS

\section{OPEN Molecular mechanism of nur77 gene expression and downstream target genes in the early stage of forskolin-induced differentiation in PC12 cells}

\author{
Hiroki Maruoka, Ryosuke Yamazoe, Ryota Takahashi, Keisuke Yatsuo, Daiki Ido, \\ Yuki Fuchigami, Fumiya Hoshikawa \& Koji Shimoke*
}

Forskolin promotes neuronal differentiation of PC12 cells via the PKA-CREB-dependent signaling pathway. Activation of PKA by forskolin phosphorylates CREB, which then binds to CRE sites in numerous gene promoters. However, it is unclear which gene contains the CRE sites responsible for forskolin-induced neuronal differentiation. In this study, we investigated how an immediate early gene, nur77, which has CRE sites in the promoter region, contributes to the early stage of differentiation of forskolin-treated PC12 cells. After treatment with forskolin, expression of Nur77 was upregulated within $1 \mathrm{hr}$. In addition, knockdown of nur77 inhibited neurite outgrowth induced by forskolin. We also revealed that the specific four CRE sites near the transcriptional start site (TSS) of nur77 were strongly associated with phosphorylated CREB within $1 \mathrm{hr}$ after treatment with forskolin. To analyze the roles of these four sites, reporter assays using the nur 77 promoter region were performed. The results showed that nur77 expression was mediated through three of the CRE sites, $-242,-222$, and -78 , and that -78 , the nearest of the three to the TSS of nur77, was particularly important. An analysis of neuronal markers controlled by Nur77 after A-CREB-Nur77-Synapsin1 signaling pathway plays a pivotal role in differentiation of forskolin-induced PC12 cells.

Low molecular weight natural products may be useful therapeutic agents for neuronal injury ${ }^{1-6}$, and some of these compounds possess neurotrophic and neuroprotective properties ${ }^{7}$. Natural products also enhance neurite outgrowth activity of nerve growth factors in experimental models ${ }^{8}$, but the detailed molecular mechanisms underlying the neurotrophic and neuroprotective effects of natural products have not been clearly defined.

One such natural product, forskolin, is a cell-permeable diterpenoid extracted from the plant Coleus forskohlii. Forskolin also has blood-brain barrier (BBB) permeability ${ }^{9}$. Therefore, forskolin is a potential therapeutic agent for nerve injury, and several studies have shown that forskolin increases the differentiation and survival of dopaminergic neurons in vitro ${ }^{10-14}$. Forskolin also induces expression of tyrosine hydroxylase in human fetal brain cortex ${ }^{15}$. In addition, forskolin increases the intracellular cAMP level by stimulation of adenylate cyclase, and cAMP-dependent signaling pathways play important roles in neuronal differentiation and neuroplasticity $^{16,17}$. Increased cAMP in cells promotes axonal regeneration and neurite outgrowth ${ }^{18-20}$, and it is well-known that cAMP promotes neurite outgrowth by binding to and activating protein kinase $\mathrm{A}(\mathrm{PKA})^{21-23}$.

Activated PKA phosphorylates cAMP response element-binding protein (CREB), which then binds to CRE (cAMP response element) sites in various gene promotor regions $\mathrm{s}^{24-26}$. Some CREB target genes have been identified as immediate early genes (IEGs) that are induced in a CRE-dependent manner. Expression of IEGs can be induced within $1 \mathrm{hr}$ in response to stimuli such as neurotrophin/Trk- or cAMP/PKA-dependent signaling pathways $^{27-32}$. Recent studies in our laboratory have shown that one IEG, nur77, is upregulated by dibutyryl-cAMP (db-cAMP) via the cAMP/PKA-dependent signaling pathway in model neuronal PC12 cells. In addition, we found that expression of Nur77 is essential for the early phase of neurite extension in PC12 cells ${ }^{20,33-35}$. 
A

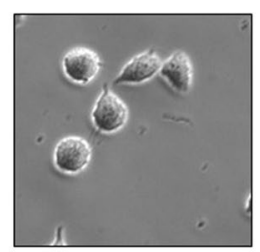

untreated

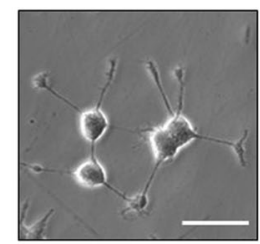

Forskolin $(10 \mu \mathrm{M})$

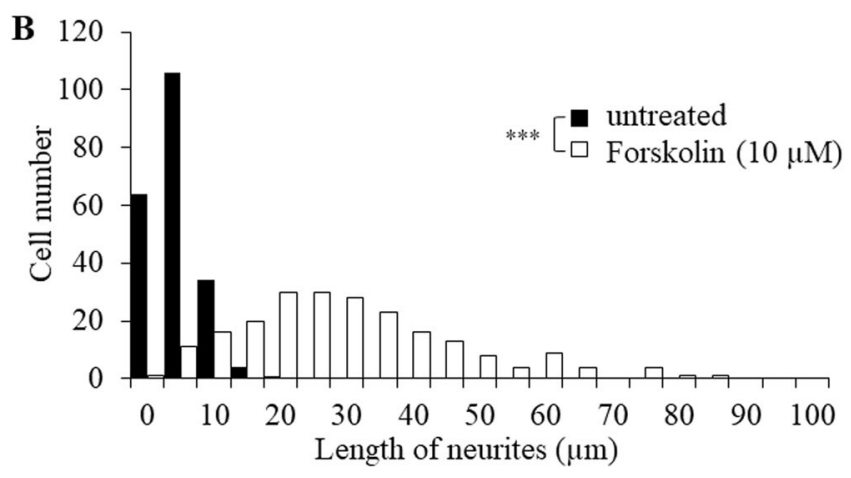

Figure 1. Nur77 is involved in neurite outgrowth induced by forskolin in PC12 cells. (A) Photomicrographs of PC12 cells cultured for $24 \mathrm{hr}$ without or with $10 \mu \mathrm{M}$ forskolin. Scale bar: $50 \mu \mathrm{m}$. (B) Histograms of neurite lengths in PC12 cells cultured for $24 \mathrm{hr}$ without (closed bars: untreated) or with $10 \mu \mathrm{M}$ forskolin (open bars: forskolin-treated). For analysis of neurite outgrowth, cells (more than 200 /well) were randomly photographed using a KEYENCE microscope. The lengths of neurite were measured using BZ-H1C software. ***P<0.001 (untreated vs. forskolin-treated cells by Kolmogorov-Smirnov test).

Nur77 is an orphan nuclear receptor that is also referred to as NGFI-B, TR3 and Nr4a1. Nur77 is a member of the Nur77 family, which also contains the orphan nuclear transcription factors Nurr-1 and Nor-1. Nur77 was originally identified as a protein that is rapidly induced by nerve growth factors in PC12 cells ${ }^{36,37}$ and by serum in fibroblasts ${ }^{38}$. Recent studies have shown that Nur77 expression is regulated by CRE-binding proteins. The nur77 gene contains four CRE sites (TGCGTCA; previously defined as the AP1 (activator protein 1) element) upstream of the transcription start site (TSS) ${ }^{26,39,40}$. These four CRE sites have been suggested to bind CREB protein ${ }^{25,26,37,41}$, and binding of transcription factors at the four CRE sites in the nur77 promoter may play an important role in the early stage of forskolin-induced neuronal differentiation. However, the detailed mechanisms of nur 77 transcription in the early phase of neurite extension are largely unknown, and the relevance of nur 77 and its transcription factors in neural differentiation is not understood.

In this study, we investigated the mechanism underlying regulation of nur77 transcription during the early phase of neurite extension induced by forskolin in PC12 cells. We found that the four CRE sites upstream of the TSS of nur77 are associated with phosphorylated CREB (P-CREB) within $1 \mathrm{hr}$ after treatment with forskolin. We also found that the $-242,-222$ and -78 CRE sites, and especially -78 , play particularly important roles. To identify the critical molecules regulated by Nur77 during forskolin-induced neurite extension, Nur77 regulation of proteins that serve as neuronal differentiation markers was analyzed. The findings showed that Nur77 regulated one such protein, Synapsin 1, but did not influence $\beta$-tubulin III or NeuroD, although it was reported that $\beta$-tubulin III or NeuroD was expressed under the Nur77 regulation. These results suggest that the PKA-CREB-Nur77-Synapsin 1 signaling pathway is essential for forskolin-induced differentiation of PC12 cells, including neurite extension.

\section{Results}

Nur77 is involved in neurite outgrowth induced by forskolin in PC12 cells. To confirm if forskolin has a role in neurite outgrowth, the lengths of neurites were measured after treatment with forskolin in PC12 cells. Neurite lengths of PC12 cells treated with $10 \mu \mathrm{M}$ forskolin for $24 \mathrm{hr}$ were significantly greater than those from untreated cells (Fig. 1A,B and see Supplementary Table S1 on line) as reported previously ${ }^{42,43}$.

Previous studies have shown that expression of nur 77 is significantly increased by db-cAMP in PC12 cells, and that Nur77 is essential for early stage of differentiation in neurons and Schwann cells ${ }^{20,34,35,44}$. To investigate whether the increased expression of Nur77 is mainly responsible for neurite outgrowth that occurs from 0 to $24 \mathrm{hr}$ after $10 \mu \mathrm{M}$ forskolin treatment, expression of nur77 gene and Nur77 induced by forskolin was examined using qPCR and immunoblotting analysis (Fig. 2A-C). The peak expression of nur77 gene and Nur77 after forskolin treatment was reached at $1-4 \mathrm{hr}$. These data suggest that expression of nur77 gene and Nur77 are induced at $0-4 \mathrm{hr}$ after $10 \mu \mathrm{M}$ forskolin treatment.

Binding of CREB with CRE sites near the TSS of nur77 is responsible for forskolin-induced Nur77 activation and neurite outgrowth. To analyze the details of the function of Nur77 in the early period of 
A

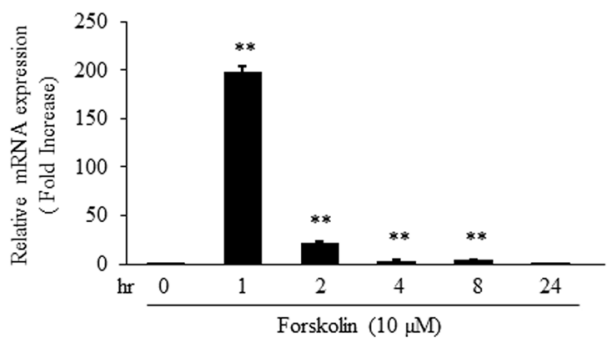

B

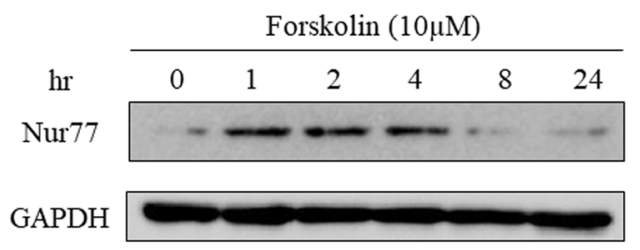

C

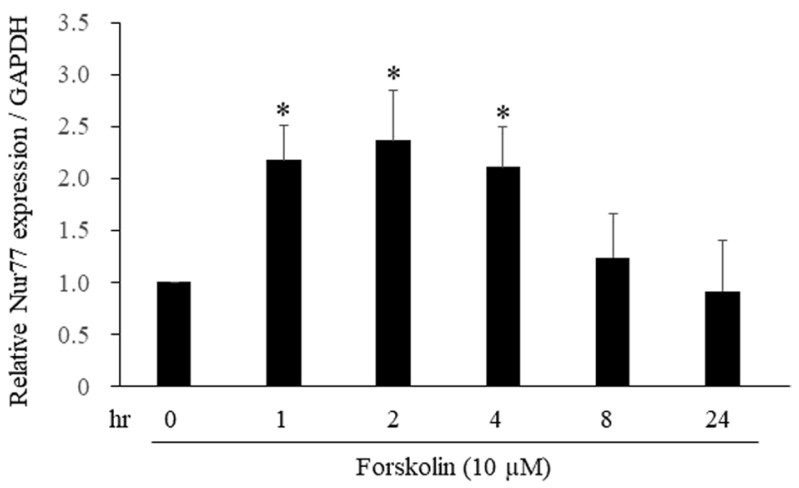

Figure 2. The expression of nur77 gene and Nur77 are induced at $0-4 \mathrm{hr}$ after $10 \mu \mathrm{M}$ forskolin treatment in PC1 2 cells. (A) PC12 cells were treated with $10 \mu \mathrm{M}$ forskolin. nur77 and gapdh mRNA were detected by qPCR as described in Methods section. nur77 mRNA levels were normalized against gapdh mRNA levels and against the initial time point $(0 \mathrm{hr}) . * * \mathrm{P}<0.01$. (B) For immunoblot analysis of forskolin-induced Nur77 in PC12 cells, cells were treated with $10 \mu \mathrm{M}$ forskolin for the indicated times in DMEM supplemented with 1\% (v/v) FBS. (C) Quantification of B, comparing the protein levels of Nur77 protein in the indicated times. The amount of Nur77 protein was quantified and normalized to that of GAPDH. $* P<0.05$ compared with $0 \mathrm{hr}$.

forskolin treatment, knockdown experiments were performed using siRNA against nur77 mRNA. First, it was confirmed that knockdown of nur77 mRNA inhibited neurite outgrowth after treatment with forskolin. Neurite length in cells treated with siRNA against nur77 mRNA in the presence of forskolin was significantly lower than that in cells treated with negative universal control siRNA (Fig. 3A,B and see Supplementary Table S2 on line). These results indicate that upregulation of Nur77 is required for differentiation of PC12 cells by $10 \mu \mathrm{M}$ forskolin.

CRE sites near the TSS are known to be heavily involved in regulation of transcription. In PC12 cells, we have shown that the CRE site-containing nur77 promoter region near the TSS is associated with acetylated Lys14 of histone H3 after treatment with db-cAMP or HDAC (Histone Deacetylase) inhibitors TSA and K350; and that expression of Nur77 induced by db-cAMP is regulated by the PKA-CREB pathway ${ }^{20,34,35}$. Based on these findings, it is likely that CRE sites upstream of the TSS of nur77 and CREB are important for nur77 expression.

To explore the role of these CREs sites and CREB in the early stage of forskolin-induced differentiation of PC12 cells, immunoblotting analysis using anti-phosphorylated CREB antibody was first performed. P-CREB was first observed $1 \mathrm{hr}$ after treatment with $10 \mu \mathrm{M}$ forskolin, similar to expression of Nur77, and phosphorylation reached a peak at $1-4 \mathrm{hr}$ and then declined to the basal level after $4 \mathrm{hr}$ (Fig. 4A,B). To examine the contribution of P-CREB to $10 \mu \mathrm{M}$ forskolin-induced nur77 expression mediated by CRE sites, a ChIP assay using anti-P-CREB and CREB antibody was carried out. This assay revealed that the nur77 promoter region containing the CRE sites (Fig. 4C) was particularly associated with P-CREB within $1 \mathrm{hr}$ after treatment with $10 \mu \mathrm{M}$ forskolin (Fig. 4D). The ChIP assay also showed that the nur77 promoter region was associated with CREB with or without $10 \mu \mathrm{M}$ forskolin treatment (Fig. 4D). Taken together, these results suggest that binding of P-CREB to the CRE sites of the nur77 promoter plays a particularly important role in mediating transcriptional activation of nur77. 
A

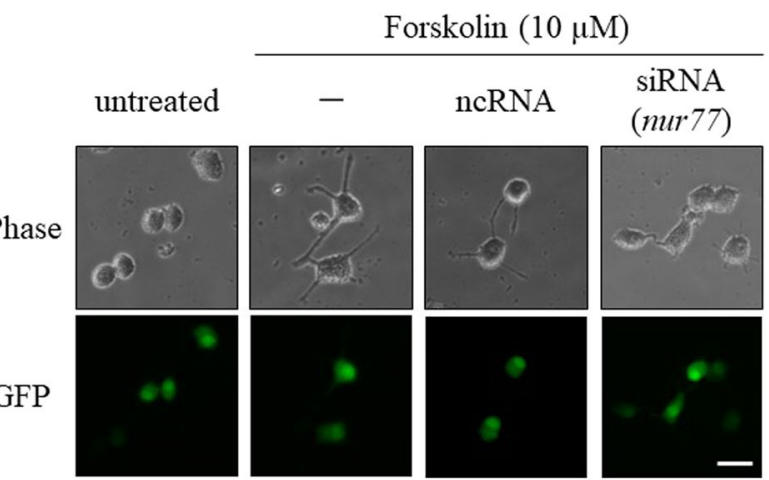

B

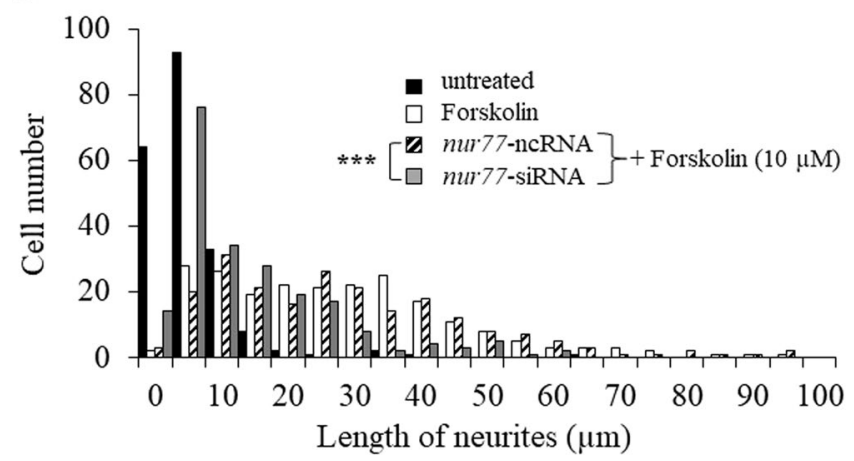

Figure 3. Nur77 is involved in forskolin-induced neurite outgrowth in PC12 cells. (A) After co-transfection with siRNAs against nur77 mRNA or ncRNA containing a GFP-expression plasmid for $48 \mathrm{hr}$, cells were treated with or without (untreated) $10 \mu \mathrm{M}$ forskolin in DMEM supplemented with $1 \%(\mathrm{v} / \mathrm{v}) \mathrm{FBS}$ for $24 \mathrm{hr}$. Phase contrast (Phase) and GFP-expression (GFP) images were detected and photographed. Scale bar: $50 \mu \mathrm{m}$. (B) Histograms of neurite lengths of forskolin-treated PC12 cells (open bars) pretreated with siRNA against nur77 mRNA (gray bars) and ncRNA control (hatched bars). PC12 cells pretreated with siRNA or ncRNA in the presence of a GFPexpression plasmid for $48 \mathrm{hr}$ were then treated with $10 \mu \mathrm{M}$ forskolin for a further $24 \mathrm{hr}$. PC12 cells were cultured without (closed bars: untreated) or with $10 \mu \mathrm{M}$ forskolin (open, hatched and gray bars). For analysis of neurite outgrowth, cells (more than 200cells /well) were randomly photographed using a KEYENCE microscope. The lengths of neurite were measured using BZ-H1C software. $* * * \mathrm{P}<0.001$ (nur77 siRNA vs. ncRNA).

To analyze the details of the role of CREB in the early period of $10 \mu \mathrm{M}$ forskolin induced nur 77 gene expression and neurite outgrowth, knockdown experiments were performed using siRNA against creb mRNA. First, we analyzed the relationship between nur77 gene expression and CREB. After treatment with creb siRNA for $24 \mathrm{hr}$ in the presence or absence of forskolin, nur 77 gene reduced strongly compared with cells treated with a negative control siRNA (Fig. 4E). Next, we confirmed that neurite length in cells treated with siRNA against creb mRNA in the presence of forskolin was significantly lower than that in cells treated with negative control siRNA (Fig. 4F,G and see Supplementary Table S3 on line). These results suggest that CREB has an important role for nur77 gene expression in differentiation of $10 \mu \mathrm{M}$ forskolin-treated PC12 cells.

CRE sites at $-242,-222$ and -78 play a pivotal role in forskolin-induced nur77 expression. The CRE sites upstream of the TSS of nur77 are located at positions $-242,-222,-78$ and -49 (Fig. 4B). To identify which of are important in Nur77 transcriptional activity induced by $10 \mu \mathrm{M}$ forskolin, a reporter assay was carried out. To analyze the role of the nur77 promoter in forskolin-induced neurite outgrowth, luciferase reporter plasmids were constructed with the four CRE sites deleted one by one (Fig. 5A). Strong Nur77-related luciferase activities were observed with the WT and -242 plasmid with or without treatment with forskolin. In contrast, the -222 , -78 and -49 plasmids had marked reduction of luciferase activity with treatment of forskolin, and -78 and -49 had reduced luciferase activity without forskolin (Fig. 5A). With plasmid -49 , luciferase activity was completely abolished. Therefore, the regulatory elements for nur77 expression appear to be present in the promoter region between -242 and -78 .

We next examined which of these three CRE sites in the promoter play significant roles in nur77 expression. As shown in Fig. 5B, luciferase activity was measured using promoter assay plasmids in which mutations were interpolated in one or two or all of the three distal CRE sites. Plasmids with a point mutation at any one of three CRE sites $-242,-222$ or -78 caused a reduction in luciferase activity under forskolin-treated condition, but particularly marked reduction occurred with the -78 mutant. In contrast, under untreated conditions, the luciferase activity was markedly reduced only with the -78 mutant. With mutants at two or three CRE sites, luciferase activity was completely abolished when a mutation at the $-78 \mathrm{CRE}$ site was included (Fig. 5B). These results suggest 
A

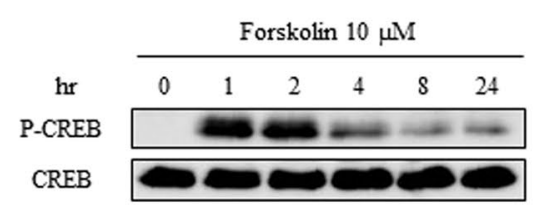

C

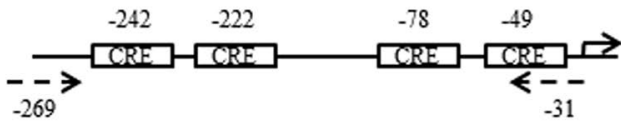

D

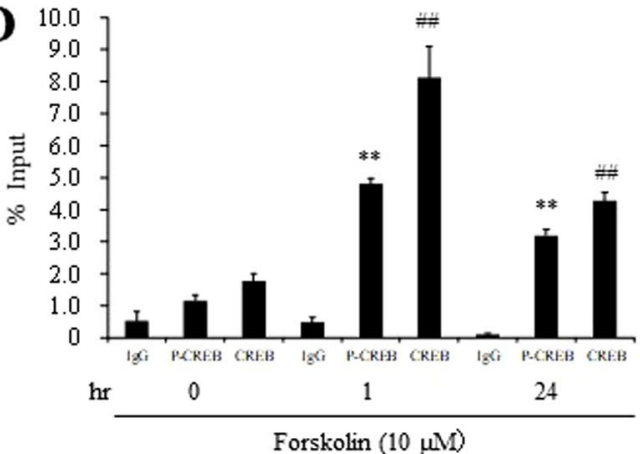

B

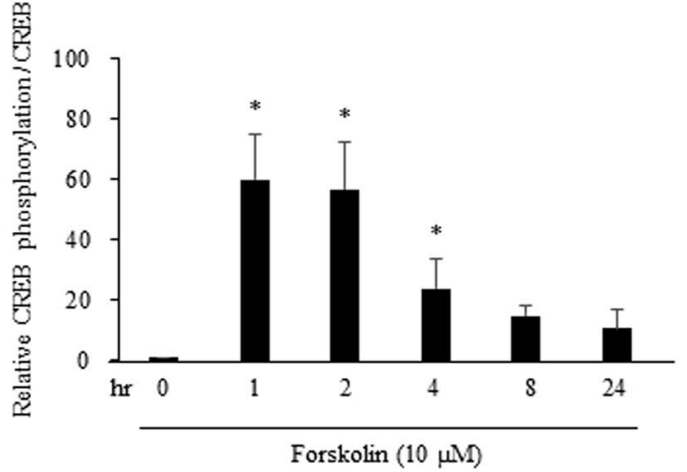

$\mathbf{E}$

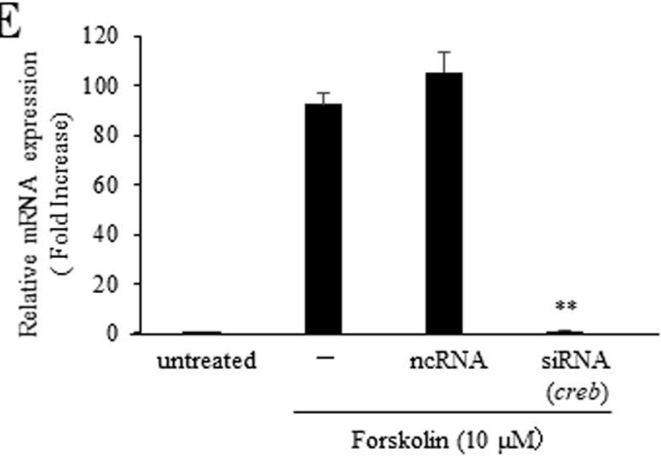

$\mathbf{F}$

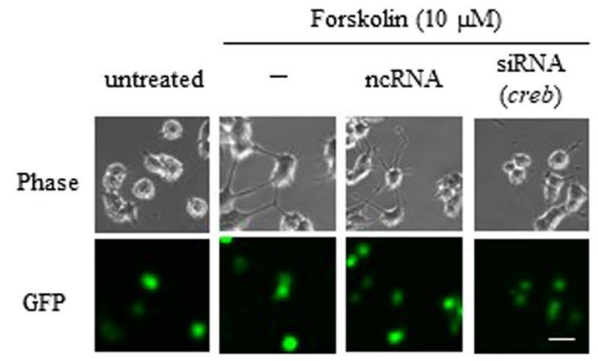

G

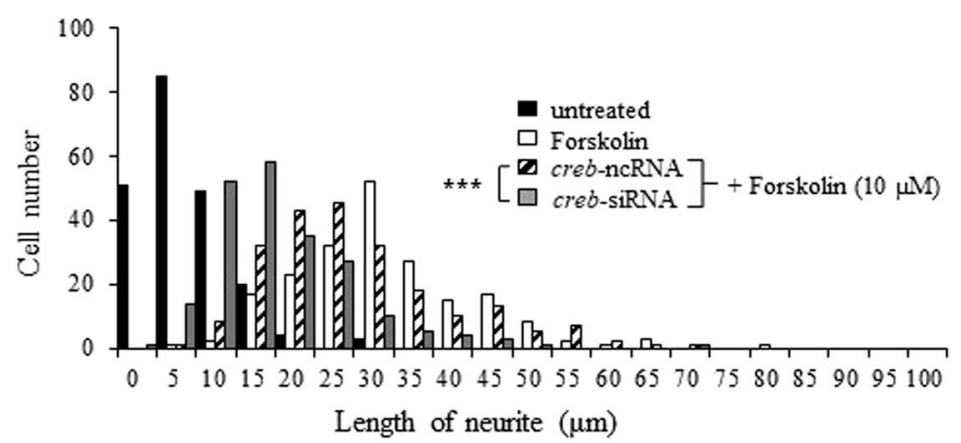

Figure 4. Binding of P-CREB to the CRE sites of the nur77 promoter plays an important role in transcriptional activation of nur77. (A) Immunoblot analysis of forskolin-induced P-CREB in PC12 cells. Cells were treated with $10 \mu \mathrm{M}$ forskolin for the indicated times. (B) Quantification of A, comparing the phosphorylation level of $\mathrm{P}-\mathrm{CREB}$ protein in the indicated times. The amount of $\mathrm{P}-\mathrm{CREB}$ protein was quantified and normalized to that of CREB. $* P<0.05$ compared to $0 \mathrm{hr}$. (C) Schematic diagram of the nur 77 gene promoter region. There are four CRE sites at $-242,-222,-78$ and -49 bp upstream of the nur 77 gene. The primers used in ChIP assays were designed to detect the region from -31 and $-269 \mathrm{bp}$ from the TSS. (D) Cells were treated with $10 \mu \mathrm{M}$ forskolin for the indicated times. Cells were then subjected to ChIP assays with an antibody against P-CREB and CREB as described in Methods. The nur77 gene promoter region was detected by qPCR. $* * \mathrm{P}<0.01$ compared with $0 \mathrm{hr}$ (P-CREB), ${ }^{\# \#} \mathrm{P}<0.01$ compared to $0 \mathrm{hr}$ (CREB). € Cells transfected with creb siRNA or ncRNA were treated with or without $10 \mu \mathrm{M}$ forskolin for $1 \mathrm{hr}$. creb and gapdh mRNA were detected by qPCR. creb mRNA were normalized against gapdh mRNA. $* * \mathrm{P}<0.01$ compared with ncRNA. (F) After co-transfection with creb siRNA or ncRNA containing a GFP-expression plasmid for $48 \mathrm{hr}$, cells were treated with or without $10 \mu \mathrm{M}$ forskolin for $24 \mathrm{hr}$. Phase contrast (Phase) and GFP-expression (GFP) images were detected and photographed. Scale bar: 50 
$\mu \mathrm{m}$. (G) Histograms of neurite lengths of forskolin-treated cells (open bars) pretreated with creb siRNA (gray bars) and ncRNA (hatched bars). Cells pretreated with siRNA or ncRNA in the presence of a GFP-expression plasmid for $48 \mathrm{hr}$ were then treated with forskolin for a further $24 \mathrm{hr}$. Cells were cultured without (closed bars: untreated) or with $10 \mu \mathrm{M}$ forskolin (open, hatched and gray bars). For analysis of neurite outgrowth, cells (more than 200 cells /well) were randomly photographed. $* * * \mathrm{P}<0.001$ (creb siRNA vs. ncRNA).

that the regulatory elements of nur77 expression are present in the promoter region between -242 and -78 , and particularly at -78 .

The Nur77-Synapsin signaling pathway is required for forskolin-dependent neuronal differentiation. The effect of Nur77 on neuron-specific markers was analyzed in neurite outgrowth induced by forskolin. We first examined if the neuron-specific marker, Synapsin 1 as a synaptic marker ${ }^{45}, \beta$-tubulin III as a neuronal marker of newly generated neurons ${ }^{46-48}$ or NeuroD as a neuronal marker for the early phase of the neuronal lineage $\mathrm{e}^{48}$, was upregulated with treatment of $10 \mu \mathrm{M}$ forskolin for $24 \mathrm{hr}$. qPCR and immunoblotting detected Synapsin 1 and $\beta$-tubulin III, but not NeuroD (Fig. 6A-C). After treatment with nur77 siRNA for $24 \mathrm{hr}$ in the presence or absence of forskolin, immunoblotting showed strong reduction of Synapsin 1 compared with cells treated with a negative control siRNA. In contrast, the $\beta$-tubulin III level was not altered by treatment with nur77 siRNA (Fig. 6D-F).

To analyze the details of the role of Synapsin 1 in the early period of $10 \mu \mathrm{M}$ forskolin treatment, knockdown experiments were performed using siRNA against synapsin 1 mRNA. We examined that neurite length in cells treated with siRNA against synapsin $1 \mathrm{mRNA}$ in the presence of forskolin was significantly lower than that in cells treated with negative control siRNA (Fig. G, H and see Supplementary Table S4 on line).

These results suggest that the Nur77-Synapsin 1 signaling pathway, but not $\beta$-tubulin III or NeuroD, has an important role in differentiation of forskolin-treated PC12 cells.

\section{Discussion}

Therapeutic agents for nerve injury must have two main characteristics of passage through the BBB and induction of neuronal differentiation. Forskolin has these properties and is also a natural product, which may reduce side effects. Therefore, this compound may be a useful drug for nerve injury. Determination of the intracellular mechanism of differentiation induced by forskolin is needed as part of the risk assessment for this potential drug. In this study, we showed that Nur77 has an important role in forskolin-induced differentiation, and we found that binding of P-CREB to the nur77 promoter region and expression of Nur77 occurred within 1 hr of forskolin treatment. In particular, we suggest that binding of P-CREB at the $-242,-222$ and -78 CRE sites among the four CRE sites in the nur77 promoter region near the TSS is essential for forskolin-induced nur77 gene activity.

The CRE sites near the TSS of nur77 have previously been shown to be important in nur77 transcription, but this study is the first to show that binding of CREB at specific CRE sites has a pivotal role in the early stage of forskolin-induced neurite outgrowth. Three of the four CRE sites in the nur77 promoter between -274 and -69 from the TSS have previously been shown to have important roles in response to extracellular stimuli $^{25,40,41}$. Similarly, our data showed that the three CRE sites at $-242,-222$ and -78 play important roles in forskolin-induced differentiation in PC12 cells (Fig. 5B). These results suggest that these three CRE sites have especially pivotal roles in nur77 expression. To understand the details of the mechanism of Nur77 expression, it will be important to know which transcription factors bind to these three CRE sites. It has recently been reported that binding of CREB to these CRE sites is enhanced by 8 Br-cAMP, PMA, EGF and TNF treatment ${ }^{25,41}$.

CREB plays an important role in differentiation and is also an essential mediator of $\mathrm{Ca}^{2+}$-activated Nur77 expression in PC12 cells and binds to the endogenous nur77 promoter region in vivo. Moreover, CRE sites in the nur77 promoter contain the central CpG that is critical for CREB binding ${ }^{25,26,49}$. Our previous data showed that the PKA-CREB-Nur77 pathway is important in neurite outgrowth in the db-cAMP-induced mechanism in PC12 cells ${ }^{20}$. Binding of Jun family proteins to CRE sites in the nur 77 promoter is also enhanced by $8 \mathrm{Br}$-cAMP ${ }^{25}$. One such protein, JunD, is an atypical member of the AP1 family that can act as both a transcriptional activator and repressor, and is also activated by an elevated level of intracellular cAMP ${ }^{50}$. c-jun, another Jun family member, is a master regulator of neurite outgrowth and axonal regeneration in nerve injury ${ }^{51,52}$. However, there is no direct evidence that binding of CREB or Jun proteins during the upregulation of Nur77 expression is involved in the differentiation, and it is uncertain of there is involvement of gene regulators other than the CREB or Jun family. Further detailed studies are required in this area.

IEGs other than Nur77 are also involved in differentiation. For example, Egr1 is an IEG that induces neuronal differentiation and causes neurite outgrowth in N2 neuroblastoma cells ${ }^{53}$. The induction of Egr 1 via the MAPK-ERK pathway has been linked to neuronal differentiation and plasticity. Two other nur77 family genes, nurr 1 and nor-1, have also been shown to act as IEGs, and are correlated with neuronal differentiation. nurr 1 is required for the development and survival of dopaminergic neurons ${ }^{54,55}$, and upregulation of nurr 1 in neuronal precursor cells promotes undifferentiated cells into mature and functional dopaminergic neurons ${ }^{56}$. Consistent with this, nurr1-deficient mice exhibit abnormal development of midbrain dopaminergic neurons ${ }^{54}$. nor-1 also plays a critical role in neuronal survival and axonal guidance in the developing murine hippocampus ${ }^{57}$, and is also involved in regulating neuronal differentiation during extension of processes in cultured fetal rat brain cells ${ }^{58}$. These findings indicate that Nur77 family members are involved in several aspects of neuronal differentiation in the developing nervous system.

Similarly to nur77, the nurr1 and nor-1 genes also have DNA motifs near the TSS that bind with transcriptional factors, such as CREB, with the transcriptional activity that is increased by phosphorylated PKA. The nurr 1 
$\mathbf{A}$

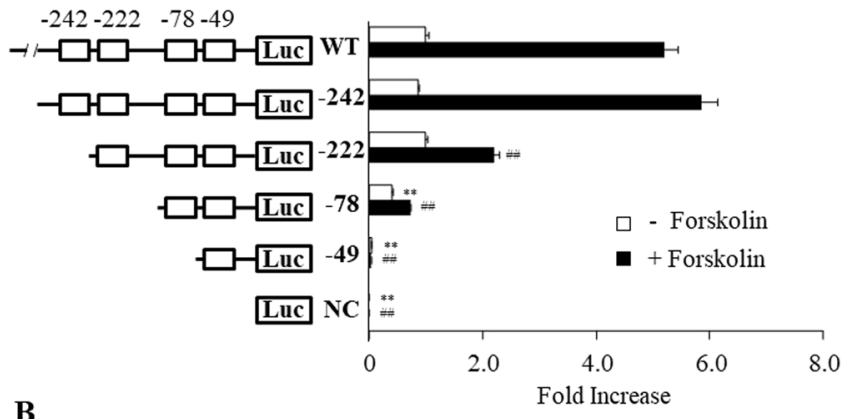

B

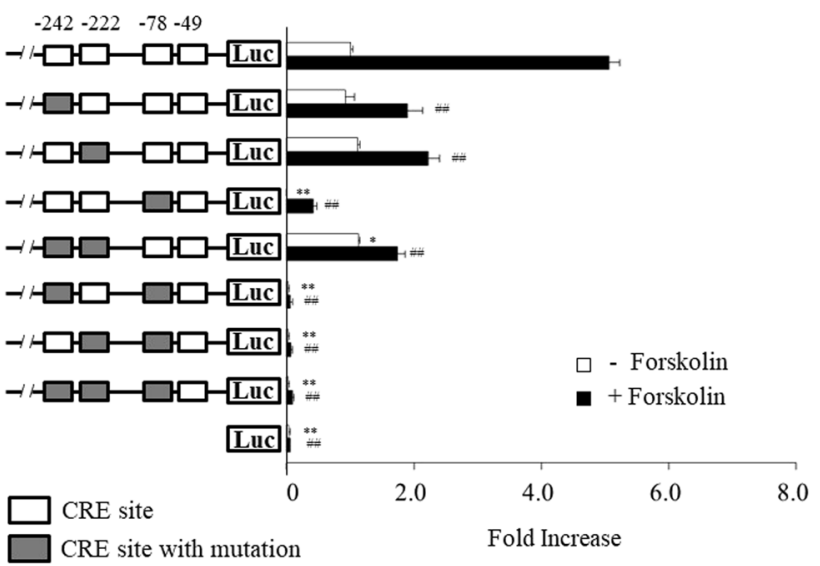

Figure 5. The promoter region between -242 and -78 , and particularly at -78 have a pivotal role of nur77 gene expression in PC12 cells. (A) Deletion analysis of Nur77 gene promoter region. Constructs used in this experiment are schematically drawn and were prepared as described in Methods. Cultured PC12 cells were transiently transfected with reporter plasmids and phRL-TK plasmid. Cells were treated with or without $10 \mu \mathrm{M}$ forskolin. Each CRE site is drawn as a square in the promoter region. $* * \mathrm{P}<0.01$ compared with WT (-Forskolin), ${ }^{\#} \mathrm{P}<0.01$ compared to WT (+Forskolin). (B) Effects of mutations in $-242,-222$ and $-78 \mathrm{CRE}$ sites within the promoter region of the rat nur77 gene. The mutant promoter plasmids positioned at -242 , -222 and -78 CRE sites are shown schematically. Mutations in CRE sites are shown as gray boxes. Cultured PC12 cells were transiently transfected with reporter plasmid and phRL-TK plasmid. Cells were treated with or without $10 \mu \mathrm{M}$ forskolin. ${ }^{* *} \mathrm{P}<0.01$ and $* \mathrm{P}<0.05$ compared to $\mathrm{WT}$ (-Forskolin), ${ }^{\# \#} \mathrm{P}<0.01$ compared with WT (+Forskolin).

promoter contains a TGACG motif near the TSS, and the nor-1 promoter has three CRE sites (TGACGTAG, TGGCGTCA, and TGACGTCT) near the TSS ${ }^{59}$. This suggests that the same transcription factor, CREB, binds to CRE sites in these Nur77 family members and may participate in neuronal differentiation. Therefore, the Nur77 family may have a common molecular mechanism in neural differentiation. However, Nur77 family members also show some differences in transcriptional activities, despite having highly homologous amino acid sequences ${ }^{41,60}$. These differences are thought to be due to the involvement of DNA binding domains other than the CRE sites. For example, nur77 and nor-1 contain binding sites for MEF2 (MEF2 response elements, MRE) near the TSS and the CRE sites in their promoter regions ${ }^{26,61}$. Early work suggested that MEF2 modulates CREB-dependent Nur77 expression by acting as a repressor in quiescent cells, while CREB is necessary for $\mathrm{Ca}^{2+}$-activated Nur77 expres$\operatorname{sion}^{26}$. Therefore, to define the relationship between the mechanism of nur77 gene expression in neuronal differentiation and the DNA motifs near the TSS, a detailed analysis of the CRE sites and the relationships between other DNA binding motifs around these sites and the relevant transcription factors is required.

In this study, we also found that the Nur77 upregulated Synapsin1, but not $\beta$-tubulin III or NeuroD, as a key step during forskolin-induced neurite outgrowth in PC12 cells. This finding provides direct evidence that Nur77 is involved in the differentiation of PC12 cells. Synapsin is an abundant pre-synaptic phosphoprotein associated with the cytoplasmic side of synaptic vesicles that promotes actin polymerization and triggers cell differentiation $^{62-65}$. Synapsin 1 is a useful indicator of PC12 cell differentiation ${ }^{66}$, and post-translational modifications of Synapsin 1 by PKA contribute to the regulation of neurotransmitter release ${ }^{67}$. These results lead us to speculate on the following model (Fig. 7). Under basal conditions, CREB binds to the promoter region of nur77 via the -78 CRE site (Fig. 7A). If forskolin activates the PKA-CREB pathway, CREB is phosphorylated and binds to CRE sites upstream of the TSS in nur77. Subsequently, Nur77 expression is induced via binding of P-CREB at the -244 , -222 , and -78 CRE sites of the nur77 promoter. Induced Nur77 may then upregulate the expression of Synapsin 1 and cause differentiation of neurons (Fig. 7B). However, it is unclear if Synapsin 1 is directly upregulated by 
A

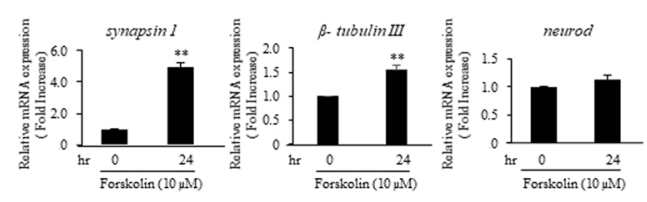

D

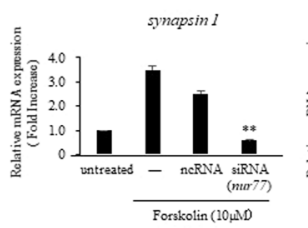

$\mathbf{G}$

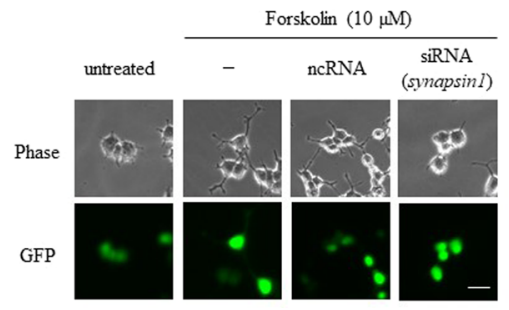

$\mathbf{E}$

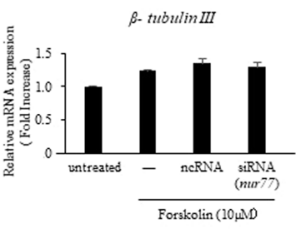

B

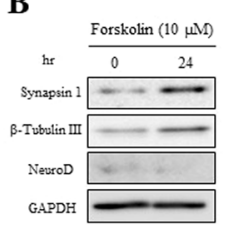

C

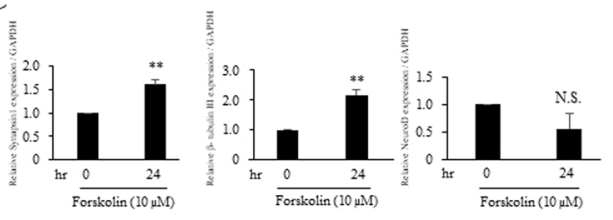

$\mathbf{F}$

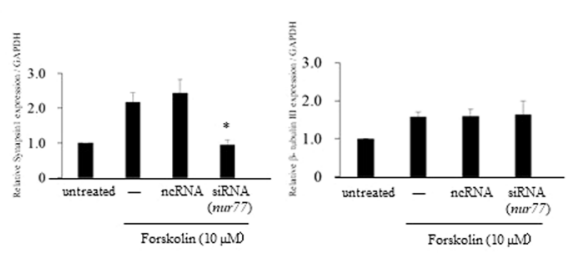

Figure 6. The Nur77-Synapsin 1 signaling pathway has an important role in differentiation of forskolin-treated PC1 2 cells. (A) Cells were treated with $10 \mu \mathrm{M}$ forskolin. synapsin1, $\beta$-tubulin III, neurod and gapdh mRNA were detected by qPCR. mRNAs were normalized against gapdh mRNA. **P $<0.01$ compared with 0 hr. (B) Immunoblot analysis of forskolin-induced Synapsin $1, \beta$-tubulin III and NeuroD. Cells were treated with $10 \mu \mathrm{M}$ forskolin for $24 \mathrm{hr}$. (C) Quantification of B, comparing the protein levels of Synapsin 1, $\beta$-tubulin III, NeuroD and GAPDH protein in the indicated times. The amount of protein was quantified and normalized to that of GAPDH. $* * \mathrm{P}<0.01$ compared with 0 hr., N.S. denotes not significant for statistical analysis. (D) Cells transfected with nur 77 siRNA were incubated in the presence or absence of $10 \mu \mathrm{M}$ forskolin for $24 \mathrm{hr}$. Synapsin 1 , $\beta$-tubulin III and gapdh mRNA were detected by qPCR. mRNAs were normalized against $g a p d h$ mRNA. $* * \mathrm{P}<0.01$ compared with untreated. (E) Cells transfected with nur77 siRNA were incubated in $10 \mu \mathrm{M}$ forskolin for $24 \mathrm{hr}$. Synapsin 1, $\beta$-tubulin III and GAPDH were detected by immunoblot analysis. These bands were representatives of three independent experiments. (F) Quantification analysis of the protein levels of Synapsin 1 and $\beta$-Tubulin III was performed $(\mathrm{n}=3)$. The amount of these protein was quantified and normalized to that of GAPDH. $* \mathrm{P}<0.05$ compared with untreated. (G) After co-transfection with synapsin 1 siRNA or ncRNA containing a GFP-expression plasmid for $48 \mathrm{hr}$, cells were treated with $10 \mu \mathrm{M}$ forskolin for $24 \mathrm{hr}$. Phase contrast (Phase) and GFP-expression (GFP) images were detected and photographed. Scale bar: $50 \mu \mathrm{m}$. (H) Histograms of neurite lengths of forskolin-treated PC12 cells (open bars) pretreated with synapsin1 siRNA (gray bars) and ncRNA (hatched bars). Cells pretreated with siRNA or ncRNA in the presence of a GFP-expression plasmid for $48 \mathrm{hr}$ were then treated with forskolin for a further $24 \mathrm{hr}$. Cells were cultured without (closed bars: untreated) or with $10 \mu \mathrm{M}$ forskolin (open, hatched and gray bars). For analysis of neurite outgrowth, cells (more than 200 cells /well) were randomly photographed. $* * * \mathrm{P}<0.001$ (synapsin1 siRNA vs. ncRNA).

Nur77 or regulated by a transcription factor controlled by Nur77. An answer to this questions requires further analysis of the molecular mechanism of the Nur77-Synapsin 1 signaling pathway in forskolin-induced neuronal differentiation.

In this study, we also revealed that NeuroD was not involved in forskolin-induced neurite outgrowth of PC12 cells. However, previous study demonstrated that Bcl-2 regulates neurite outgrowth through the Bmp4 - Tbx3 NeuroD1 cascade in H19-7 cells ${ }^{68}$. In addition, it has been known that Nur77 is localized to the mitochondria, inducing the release of Cytochrome $\mathrm{C}$ and Caspase 3 through interaction with $\mathrm{Bcl}-2$. This molecular interaction causes apoptosis in following apoptosis stimulation ${ }^{69,70}$. These findings suggest that the function or the expression of NeuroD may be regulated by Nur77 in neurite outgrowth that does not involve in the PKA-CREB pathway. Furthermore, we demonstrated that $\beta$-tubulin III was not regulated by Nur77 in forskolin-induced neurite outgrowth of PC12 cells. On the other hand, Damodaran et al. have reported that phosphorylation of CREB by PKA and a member of the CaMK family, CaMKII play a crucial role in the altered axonal transport by modulating the transcription of $\beta$-tubulin gene ${ }^{71}$. In addition, it has also been shown that CaMKI pathway contributes to cAMP-induced Nur77 expression in MA-10 Leydig cells ${ }^{72}$. These findings suggest that Nur77 may regulate the expression of tubulin in neurite outgrowth induced by activators of the PKA-CREB pathway. There are numerous genes that are regulated by Nur77 in neural differentiation, and their regulatory mechanisms are still unclear. Therefore, we need more detailed analyses about the downstream molecules of Nur77 in future. 
A

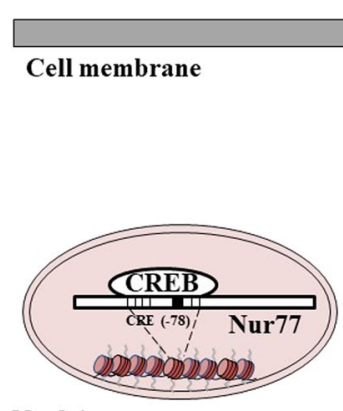

B

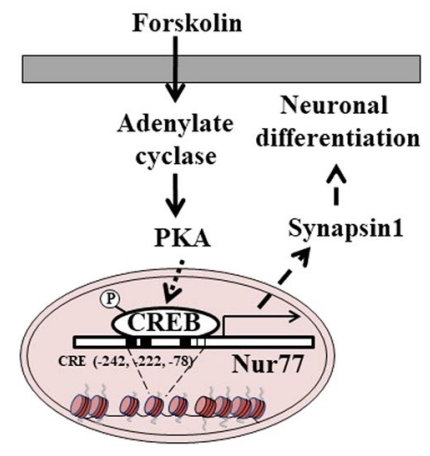

Figure 7. The nur77 gene expression-dependent molecular pathway to forskolin-induced neuronal outgrowth. (A) In the forskolin-untreated (basal) condition, CREB binds to the -78 CRE site (black closed box in the nucleus) in the nur77 promoter region, causing expression of Nur77. (B) After stimulation with forskolin, the PKA-CREB pathway is activated through adenylate cyclase production. Then, CREB is phosphorylated (P-CREB) and the P-CREB binds to the three CRE sites in the nur77 gene upstream of the TSS. The binding sites $(-242,-222$ and -78$)$ are shown as black closed boxes in the nucleus. Binding of phosphorylated CREB to the nur77 gene promoter region strongly induces Nur77 expression, after which Nur77 upregulates expression of Synapsin 1 to promote differentiation of PC12 cells.

The findings in this study reveal that the PKA-CREB-Nur77 pathway is essential for forskolin-induced differentiation of PC12 cells. We also showed that expression of nur77 is initiated by binding of CREB to the CRE sites $-242,-222$ and -78 , and especially -78 , in the nur77 promoter region near the TSS. We also found that Nur77 upregulated Synapsin1, a neuronal differentiation marker. Further detailed studies are needed to define the molecular mechanisms of Nur77-mediated differentiation induced by forskolin.

\section{Methods}

Cell culture. PC12 cells were maintained in Dulbecco's modified Eagle's medium (DMEM) supplemented with $5 \%(\mathrm{v} / \mathrm{v})$ fetal bovine serum (FBS) (Sigma, MO, USA), 5\% (v/v) horse serum, $10 \mathrm{mM}$ HEPES (pH7.0) and $0.1 \%(\mathrm{v} / \mathrm{v})$ penicillin-streptomycin (Gibco BRL, Carlsbad, CA).

Measurement of neurite outgrowth. Cells were seeded in 24-well plates at $1.5 \times 10^{4} \mathrm{cells} / \mathrm{cm}^{2}$. After $16 \mathrm{hr}$, the medium was replaced with DMEM in the presence or absence of $10 \mu \mathrm{M}$ forskolin (Sigma, MO, USA) supplemented with $1 \%(\mathrm{v} / \mathrm{v})$ FBS. The cells were then further incubated for $24 \mathrm{hr}$ and fixed with $4 \%$ paraformaldehyde for $30 \mathrm{~min}$. For analysis of neurite outgrowth, cells (more than 200 /well) were randomly photographed using a KEYENCE microscope (Biozero BZ-9100, Osaka, Japan). Neurite lengths were measured using the BZ-H1C software. All measurements were made in duplicate. Differences between groups were compared by Kolmogorov-Smirnov test, with $\mathrm{P}<0.001$ considered to denote a significant difference.

Knockdown experiments. $\quad$ siRNA constructs targeting of the nur77 gene (sense: UCC AGU GGC UCU GAU UAC UAU GGA A antisense: UUC CAU AGU AAU CAG AGC CAC UGG A) ${ }^{20}$, the creb gene (siRNA ID: s135440), the synapsin 1 gene (siRNA ID: s128739), and a negative universal control (Cat\# 46-537) (ncRNA) were obtained from Life Technologies (Carlsbad, CA). We confirmed that these siRNAs sufficiently reduced target gene expressions using qPCR (see Supplementary Fig. S1 on line).

Cells were seeded onto 6 -well plates at $1.0 \times 10^{5} \mathrm{cell} / \mathrm{cm}^{2}$ and incubated for $16 \mathrm{hr}$, and then transfected with $100 \mathrm{nM}$ nur77 siRNA and $5 \mathrm{nM}$ creb and synapsin1 siRNA or with ncRNA using Lipofectamine ${ }^{\circledR}$ RNAiMAX (Life Technologies). After $48 \mathrm{hr}$, the medium was replaced with $10 \mu \mathrm{M}$ forskolin in DMEM supplemented with $1 \%$ $(\mathrm{v} / \mathrm{v}) \mathrm{FBS}$, and the cells were incubated for a further $1 \mathrm{hr}$ and $24 \mathrm{hr}$. Then, the cells were used for RNA extraction or immunoblot analysis.

For measurement of neurite lengths of PC12 cells transfected with siRNAs directed against target mRNAs, the cells were plated onto 24 -well plates at $1.5 \times 10^{4} \mathrm{cells} / \mathrm{cm}^{2}$ and incubated for $16 \mathrm{hr}$. We then co-transfected siRNAs $(100 \mathrm{nM})$ against target mRNAs with $0.125 \mathrm{nM}$ pCX-EGFP using Lipofectamine ${ }^{\circledR}$ RNAiMAX (Life Technologies). After $48 \mathrm{hr}$, the cells were treated with $10 \mu \mathrm{M}$ forskolin in DMEM supplemented with $1 \%(\mathrm{v} / \mathrm{v}) \mathrm{FBS}$ and incubated for another $24 \mathrm{hr}$, and then fixed with $4 \%(\mathrm{w} / \mathrm{v})$ paraformaldehyde for $30 \mathrm{~min}$. For analysis of neurite outgrowth, GFP-positive cells (more than 200 /well) were randomly photographed and measured $24 \mathrm{hr}$ after initial treatment with forskolin. All measurements were made in duplicate.

RNA extraction and Quantitative real-time PCR (qPCR). Total RNA was collected with ISOGEN (Nippongene, Toyama, Japan) and extracted with phenol-chloroform. cDNA was then synthesized using the ReverTraAce ${ }^{\circledR}$ qPCR RT Kit (TOYOBO, Osaka, Japan). 25 ng of cDNA was used as template for StepOnePlus ${ }^{\mathrm{TM}}$ real-time PCR system (Applied Biosystems, USA) using THUNDERBIRD ${ }^{\circledR}$ Probe qPCR Mix (TOYOBO, Osaka, Japan). 
The data were analyzed with delta delta Ct method and normalized to the amounts of gapdh RNA expression in each sample. PCR primers used were those of TaqMan ${ }^{\circledR}$ gene expression assay kits for $n u r 77$ (Assay ID: Rn00666994_g1), creb (Assay ID: Rn06140207_g1), synapsin1 (Assay ID: Rn00569468_m1), tubulin, beta 3 class III (Assay ID: Rn01431594_m1), neurod1 (Assay ID: Rn00824571_s1), and gapdh (Assay ID: Rn01775763_g1). All measurements were made in triplicate. Data are presented as the mean $\pm \operatorname{SEM}(n=3)$. Statistical significance for each time was determined by Student's t-test. $* * \mathrm{p}<0.01$.

Immunoblot analysis. Cells were seeded onto $6 \mathrm{~cm}$ dishes at $1.0 \times 10^{5} \mathrm{cell} / \mathrm{cm}^{2}$. After $16 \mathrm{hr}$, the medium was replaced with DMEM supplemented with $1 \%(\mathrm{v} / \mathrm{v}) \mathrm{FBS}$, and the cells were then treated with $10 \mu \mathrm{M}$ forskolin for $0-24 \mathrm{hr}$, respectively. Immunoblot analysis were performed as described previously ${ }^{73}$. The first antibody (anti-phospho CREB (Ser133) antibody (Merck), anti-CREB antibody (Cell Signaling Technology, Danvers, MA, USA), anti-Nur77 antibody (Abcam, Cambridge, UK), anti-Synapsin1 antibody (Abcam), anti-NeuroD antibody (Cell Signaling Technology), anti- $\beta$-tubulin III antibody (Sigma) or anti-GAPDH antibody (Merck)) was loaded onto the membrane after blocking with $5 \%$ skimmed-milk (Nakarai, Kyoto, Japan), followed by incubation with a horseradish peroxidase-conjugated secondary antibody (MBL CO., LTD., Nagoya, Japan). The bands were detected by ECL Select Western Blotting Detection System Reagent or ECL Prime Western Blotting Detection System Reagent and visualized with an Image Quant LAS 4000 (all GE Healthcare Life Sciences, Little Chalfont, UK). All measurements were made in triplicate. Quantitative analysis was performed by determining the immunofluorescence intensity of the target protein(s) using ImageJ. Data are presented as the mean \pm SEM $(n=3)$. Statistical significance for each time was determined by Student's t-test. $* \mathrm{p}<0.05$.

Chromatin immunoprecipitation (ChIP) assay. ChIP assays were performed as described previously ${ }^{20}$ with some modifications. The diluted chromatin of $5 \times 10^{6}$ cells was incubated with anti-phospho CREB (Ser133) antibody (Merck), anti-CREB antibody (Cell Signaling Technology) or normal rabbit IgG (Cell Signaling Technology) for $12-16 \mathrm{hr}$ at $4^{\circ} \mathrm{C}$. Immune complexes were bound to Protein $\mathrm{G}$ sepharose beads preblocked with salmon sperm DNA and bovine serum albumin for $120 \mathrm{~min}$ at $4^{\circ} \mathrm{C}$. The beads were washed once each with low-salt wash buffer $(0.1 \%$ (w/v) SDS, $1 \%$ (v/v) Triton-X100, 2 mM EDTA, $150 \mathrm{mM} \mathrm{NaCl}$, and $20 \mathrm{mM}$ Tris- $\mathrm{HCl}$ at $\mathrm{pH} 8.0)$, high-salt wash buffer $(500 \mathrm{mM} \mathrm{NaCl}$ wash buffer), $\mathrm{LiCl}$ wash buffer $(0.25 \mathrm{M} \mathrm{LiCl}, 1 \% \mathrm{NP}-40,1 \%(\mathrm{v} / \mathrm{v})$ deoxycholate, $1 \mathrm{mM}$ EDTA, and $10 \mathrm{mM}$ Tris- $\mathrm{HCl}$ at $\mathrm{pH} 8.0)$, and twice with TE buffer $(10 \mathrm{mM}$ Tris- $\mathrm{HCl}$ at $\mathrm{pH} 8.0$ and $1 \mathrm{mM}$ EDTA). Immune complexes bound to Protein $\mathrm{G}$ beads were incubated overnight at $65^{\circ} \mathrm{C}$ and treated with $100 \mu \mathrm{g} / \mathrm{ml}$ proteinase $\mathrm{K}$ for $1 \mathrm{hr}$ at $56^{\circ} \mathrm{C}$ before extraction once with phenol/chloroform. The DNA was then precipitated with ethanol containing glycogen as a carrier and resuspended in $20 \mu \mathrm{of} \mathrm{dH}_{2} \mathrm{O}$. DNA was analyzed by qPCR using following PCR probes (sense: GAT CAA ACA ATC CGC GCT CCC anti-sense: CAC CTC TTA AGC GCT CCG TGA, and TaqMan ${ }^{\circledR}$ MGB probe: TAT GGC CAA AGC TC). The ChIP enriched DNA levels were then normalized to input DNA. All measurements were made in duplicate. Data are presented as the mean $\pm \operatorname{SEM}(\mathrm{n}=3)$. Statistical significance was determined by Student's t-test. ${ }^{* *} \mathrm{p}<0.01,{ }^{\# \#} \mathrm{p}<0.01$.

Luciferase assays. A promoter region of the rat nur77 gene (WT) was cloned from rat genome DNA using PCR and KOD Plus (TOYOBO) and inserted into a pGL3 basic plasmid vector (Promega, Madison, WI, USA) at Kpn I and Hind III sites. Reporter plasmids constructed of fragments of the rat nur77 promoter region $(-242$, $-222,-78,-49)$ were obtained using a KOD-Plus Mutagenesis Kit (TOYOBO). Promoter fragments were generated by PCR using the following primers: GCG GGT ACC CAG GGC TTG GGG TAG GGG TGG (WT promoter forward primer), GCG AAG CTT CGG CCG GCT CCC GCT CCC CGT (WT promoter reverse primer), CCG CGC TCC CTG CGT CAA TGG (-242 promoter forward primer), GGT ACC TAT CGA TAG AGA AAT GTT CTG GC ( -242 promoter reverse primer), GAA CCC CGC GTG CGT CAC GC ( -222 promoter forward primer), GGT ACC TAT CGA TAG AGA AAT GTT CTG GC ( -222 promoter reverse primer), CCG GGC CGT GTG CGT CAG TG ( -78 promoter forward primer), GGT ACC TAT CGA TAG AGA AAT GTT CTG GC $(-78$ promoter reverse primer), CCC CTC TCC ATG CGT CAC GGA GC ( -49 promoter forward primer) and GGT ACC TAT CGA TAG AGA AAT GTT CTG GC ( -49 promoter reverse primer).

Site-directed mutagenesis of CRE sites within the $-242,-222$ and -78 nur77 promoters was also achieved using the KOD-Plus Mutagenesis Kit (TOYOBO). Promoter fragments containing substituted nucleotide sequences were generated by PCR using the following primers: TGA TGG AAC CCC GCG TGC GT $(-242$ promoter forward primer), ACG CAG GGA GCG CGG ATT G (-242 promoter reverse primer), TGC GCG CGC AGA CAT TCC AGG C (-222 promoter forward primer), ACG CAC GCG GGG TTC CAT TGA C ( -222 promoter reverse primer), TGG TGG CGC CCC CGC CCC TCT C ( -78 promoter forward primer), and ACG CAC ACG GCC CGG CGA GC ( -78 promoter reverse primer). The nucleotide sequences of all inserts were confirmed using a 3130xl Genetic Analyzer (Thermo Fisher Scientific, MA, USA).

Plasmids with the appropriate nur77 promoters were transfected with the phRL-TK plasmid (Promega) using Lipofectamine 2000 (Life Technologies). After $48 \mathrm{hr}$, transfected cells were then established as untreated or stimulated cells for $1 \mathrm{hr}$ with $10 \mu \mathrm{M}$ forskolin. After stimulation, the cells were lysed and the activities of firefly and Renilla luciferase were measured using the Dual-luciferase reporter assay system (Promega). Firefly luciferase activities were normalized to the Renilla control. All measurements were made in duplicate. Data are presented as the mean $\pm \operatorname{SEM}(\mathrm{n}=3)$. Statistical significance for each time was determined by Student's t-test. ** $\mathrm{p}<0.01$, $\# \mathrm{p}<0.01$ and $* \mathrm{p}<0.05$.

Received: 8 July 2019; Accepted: 23 March 2020; Published online: 14 April 2020 


\section{References}

1. Tohda, C., Kuboyama, T. \& Komatsu, K. Search for natural products related to regeneration of the neuronal network. Neuro-Signals 14, 34-45, https://doi.org/10.1159/000085384 (2005).

2. Li, P., Yamakuni, T., Matsunaga, K., Kondo, S. \& Ohizumi, Y. Nardosinone enhances nerve growth factor-induced neurite outgrowth in a mitogen-activated protein kinase- and protein kinase C-dependent manner in PC12D cells. Journal of pharmacological sciences 93, 122-125 (2003).

3. Sagara, Y., Vanhnasy, J. \& Maher, P. Induction of PC12 cell differentiation by flavonoids is dependent upon extracellular signalregulated kinase activation. Journal of neurochemistry 90, 1144-1155, https://doi.org/10.1111/j.1471-4159.2004.02563.x (2004).

4. Guo, Y. et al. Iridoids and sesquiterpenoids with NGF-potentiating activity from the rhizomes and roots of Valeriana fauriei. Chemical \& pharmaceutical bulletin 54, 123-125 (2006).

5. Kano, Y. et al. Artepillin C derived from propolis induces neurite outgrowth in PC12m 3 cells via ERK and p38 MAPK pathways. Neurochemical research 33, 1795-1803, https://doi.org/10.1007/s11064-008-9633-9 (2008).

6. Shibata, T. et al. A food-derived synergist of NGF signaling: identification of protein tyrosine phosphatase $1 \mathrm{~B}$ as a key regulator of NGF receptor-initiated signal transduction. Journal of neurochemistry 107, 1248-1260, https://doi. org/10.1111/j.1471-4159.2008.05686.x (2008).

7. More, S. V. et al. The role of bioactive compounds on the promotion of neurite outgrowth. Molecules 17, 6728-6753, https://doi. org/10.3390/molecules17066728 (2012).

8. Li, P., Matsunaga, K., Yamakuni, T. \& Ohizumi, Y. Picrosides I and II, selective enhancers of the mitogen-activated protein kinasedependent signaling pathway in the action of neuritogenic substances on PC12D cells. Life sciences 71, 1821-1835 (2002).

9. Wysham, D. G., Brotherton, A. F. \& Heistad, D. D. Effects of forskolin on cerebral blood flow: implications for a role of adenylate cyclase. Stroke; a journal of cerebral circulation 17, 1299-1303 (1986).

10. Engele, J. \& Franke, B. Effects of glial cell line-derived neurotrophic factor (GDNF) on dopaminergic neurons require concurrent activation of cAMP-dependent signaling pathways. Cell and tissue research 286, 235-240 (1996).

11. Riaz, S. S., Jauniaux, E., Stern, G. M. \& Bradford, H. F. The controlled conversion of human neural progenitor cells derived from foetal ventral mesencephalon into dopaminergic neurons in vitro. Brain research. Developmental brain research 136, 27-34 (2002).

12. Lara, J., Kusano, K., House, S. \& Gainer, H. Interactions of cyclic adenosine monophosphate, brain-derived neurotrophic factor, and glial cell line-derived neurotrophic factor treatment on the survival and growth of postnatal mesencephalic dopamine neurons in vitro. Experimental neurology 180, 32-45 (2003).

13. Wang, T., Liu, B., Zhang, W., Wilson, B. \& Hong, J. S. Andrographolide reduces inflammation-mediated dopaminergic neurodegeneration in mesencephalic neuron-glia cultures by inhibiting microglial activation. The Journal of pharmacology and experimental therapeutics 308, 975-983, https://doi.org/10.1124/jpet.103.059683 (2004).

14. Christophersen, N. S. et al. Induction of dopaminergic neurons from growth factor expanded neural stem/progenitor cell cultures derived from human first trimester forebrain. Brain research bulletin 70, 457-466, https://doi.org/10.1016/j.brainresbull.2006.07.001 (2006).

15. Pliego Rivero, F. B., McCormack, W. J., Jauniaux, E., Stern, G. M. \& Bradford, H. F. Forskolin-induced expression of tyrosine hydroxylase in human foetal brain cortex. Brain research. Developmental brain research 114, 201-206 (1999).

16. Michel, P. P. \& Agid, Y. Chronic activation of the cyclic AMP signaling pathway promotes development and long-term survival of mesencephalic dopaminergic neurons. Journal of neurochemistry 67, 1633-1642 (1996).

17. Branton, R. L., Love, R. M. \& Clarke, D. J. cAMP included during cell suspension preparation improves survival of dopaminergic neurons in vitro. Neuroreport 9, 3223-3227 (1998).

18. Lu, P., Yang, H., Jones, L. L., Filbin, M. T. \& Tuszynski, M. H. Combinatorial therapy with neurotrophins and cAMP promotes axonal regeneration beyond sites of spinal cord injury. The. Journal of neuroscience: the official journal of the Society for Neuroscience 24, 6402-6409, https://doi.org/10.1523/JNEUROSCI.1492-04.2004 (2004).

19. Pearse, D. D. et al. cAMP and Schwann cells promote axonal growth and functional recovery after spinal cord injury. Nature medicine 10, 610-616, https://doi.org/10.1038/nm1056 (2004).

20. Maruoka, H. et al. Dibutyryl-cAMP up-regulates nur77 expression via histone modification during neurite outgrowth in PC12 cells. Journal of biochemistry 148, 93-101, https://doi.org/10.1093/jb/mvq036 (2010).

21. Ming, G. L. et al. cAMP-dependent growth cone guidance by netrin-1. Neuron 19, 1225-1235 (1997).

22. Song, H. J., Ming, G. L. \& Poo, M. M. cAMP-induced switching in turning direction of nerve growth cones. Nature 388, 275-279, https://doi.org/10.1038/40864 (1997).

23. Song, H. J. \& Poo, M. M. Signal transduction underlying growth cone guidance by diffusible factors. Current opinion in neurobiology 9, 355-363 (1999).

24. Kim, M. K., McClaskey, J. H., Bodenner, D. L. \& Weintraub, B. D. An AP-1-like factor and the pituitary-specific factor Pit-1 are both necessary to mediate hormonal induction of human thyrotropin beta gene expression. The Journal of biological chemistry 268, 23366-23375 (1993).

25. Inaoka, Y. et al. Regulation of NGFI-B/Nur77 gene expression in the rat ovary and in leydig tumor cells MA-10. Molecular reproduction and development 75, 931-939, https://doi.org/10.1002/mrd.20788 (2008).

26. Lam, B. Y. et al. CREB-dependent Nur77 induction following depolarization in PC12 cells and neurons is modulated by MEF2 transcription factors. Journal of neurochemistry 112, 1065-1073, https://doi.org/10.1111/j.1471-4159.2009.06521.x (2010).

27. Matheny, C., DiStefano, P. S. \& Milbrandt, J. Differential activation of NGF receptor and early response genes in neural crest-derived cells. Brain research. Molecular brain research 13, 75-81 (1992).

28. Kim, J. Y. et al. Activation of neurotrophin-3 receptor TrkC induces apoptosis in medulloblastomas. Cancer research 59, 711-719 (1999).

29. Stork, P. J. \& Schmitt, J. M. Crosstalk between cAMP and MAP kinase signaling in the regulation of cell proliferation. Trends in cell biology 12, 258-266 (2002).

30. Howe, A. K. Regulation of actin-based cell migration by cAMP/PKA. Biochimica et biophysica acta 1692, 159-174, https://doi. org/10.1016/j.bbamcr.2004.03.005 (2004).

31. Johannessen, M., Delghandi, M. P., Seternes, O. M., Johansen, B. \& Moens, U. Synergistic activation of CREB-mediated transcription by forskolin and phorbol ester requires PKC and depends on the glutamine-rich Q2 transactivation domain. Cellular signalling 16, 1187-1199, https://doi.org/10.1016/j.cellsig.2004.03.009 (2004).

32. Eggert, A. et al. Molecular dissection of TrkA signal transduction pathways mediating differentiation in human neuroblastoma cells. Oncogene 19, 2043-2051, https://doi.org/10.1038/sj.onc.1203518 (2000).

33. Maruoka, H., Sasaya, H., Sugihara, K., Shimoke, K. \& Ikeuchi, T. Low-molecular-weight compounds having neurotrophic activity in cultured PC12 cells and neurons. Journal of biochemistry 150, 473-475, https://doi.org/10.1093/jb/mvr113 (2011).

34. Maruoka, H. et al. New Orally Bioavailable 2-aminobenzamide-type Histone Deacetyase Inhibitor Promotes Neurite Outgrowth via Histone H3 Modification in PC12 cells: a Possible Therapeutic Candidate for Neuronal Diseases. J. Bioengineer. Biomed. Science, https://doi.org/10.4172/2155-9538.S5-001 (2012).

35. Tomioka, T. et al. The histone deacetylase inhibitor trichostatin A induces neurite outgrowth in PC12 cells via the epigenetically regulated expression of the nur77 gene. Neuroscience research 88, 39-48, https://doi.org/10.1016/j.neures.2014.07.009 (2014).

36. Milbrandt, J. Nerve growth factor induces a gene homologous to the glucocorticoid receptor gene. Neuron 1, 183-188 (1988). 
37. Yoon, J. K. \& Lau, L. F. Transcriptional activation of the inducible nuclear receptor gene nur77 by nerve growth factor and membrane depolarization in PC12 cells. The Journal of biological chemistry 268, 9148-9155 (1993).

38. Hazel, T. G., Nathans, D. \& Lau, L. F. A gene inducible by serum growth factors encodes a member of the steroid and thyroid hormone receptor superfamily. Proceedings of the National Academy of Sciences of the United States of America 85, 8444-8448 (1988).

39. Fass, D. M., Butler, J. E. \& Goodman, R. H. Deacetylase activity is required for cAMP activation of a subset of CREB target genes. The Journal of biological chemistry 278, 43014-43019, https://doi.org/10.1074/jbc.M305905200 (2003).

40. Yoon, J. K. \& Lau, L. F. Involvement of JunD in transcriptional activation of the orphan receptor gene nur77 by nerve growth factor and membrane depolarization in PC12 cells. Molecular and cellular biology 14, 7731-7743 (1994).

41. Darragh, J. et al. MSKs are required for the transcription of the nuclear orphan receptors Nur77, Nurr1 and Nor1 downstream of MAPK signalling. The Biochemical journal 390, 749-759, https://doi.org/10.1042/BJ20050196 (2005).

42. Ma, S., Liu, G., Sun, Y. \& Xie, J. Relocalization of the polypyrimidine tract-binding protein during PKA-induced neurite growth. Biochimica et biophysica acta 1773, 912-923, https://doi.org/10.1016/j.bbamcr.2007.02.006 (2007).

43. Cao, W., Razanau, A., Feng, D., Lobo, V. G. \& Xie, J. Control of alternative splicing by forskolin through hnRNP K during neuronal differentiation. Nucleic Acids Res 40, 8059-8071, https://doi.org/10.1093/nar/gks504 (2012).

44. Zhang, W. et al. Nur77 Was Essential for Neurite Outgrowth and Involved in Schwann Cell Differentiation After Sciatic Nerve Injury. Journal of molecular neuroscience: MN 57, 38-47, https://doi.org/10.1007/s12031-015-0575-9 (2015).

45. Li, Y. et al. Long-term neurocognitive dysfunction in offspring via NGF/ ERK/CREB signaling pathway caused by ketamine exposure during the second trimester of pregnancy in rats. Oncotarget 8, 30956-30970, https://doi.org/10.18632/oncotarget.16042 (2017).

46. Menezes, J. R. \& Luskin, M. B. Expression of neuron-specific tubulin defines a novel population in the proliferative layers of the developing telencephalon. The Journal of neuroscience: the official journal of the Society for Neuroscience 14, 5399-5416 (1994).

47. von Bohlen Und Halbach, O. Immunohistological markers for staging neurogenesis in adult hippocampus. Cell and tissue research 329, 409-420, https://doi.org/10.1007/s00441-007-0432-4 (2007).

48. von Bohlen und Halbach, O. Immunohistological markers for proliferative events, gliogenesis, and neurogenesis within the adult hippocampus. Cell and tissue research 345, 1-19, https://doi.org/10.1007/s00441-011-1196-4 (2011).

49. Impey, S. et al. Defining the CREB regulon: a genome-wide analysis of transcription factor regulatory regions. Cell 119, 1041-1054, https://doi.org/10.1016/j.cell.2004.10.032 (2004).

50. Hernandez, J. M., Floyd, D. H., Weilbaecher, K. N., Green, P. L. \& Boris-Lawrie, K. Multiple facets of junD gene expression are atypical among AP-1 family members. Oncogene 27, 4757-4767, https://doi.org/10.1038/onc.2008.120 (2008).

51. Arthur-Farraj, P. J. et al. c-Jun reprograms Schwann cells of injured nerves to generate a repair cell essential for regeneration. Neuron 75, 633-647, https://doi.org/10.1016/j.neuron.2012.06.021 (2012).

52. Huang, L. et al. c-Jun gene-modified Schwann cells: upregulating multiple neurotrophic factors and promoting neurite outgrowth. Tissue engineering. Part A 21, 1409-1421, https://doi.org/10.1089/ten.TEA.2014.0416 (2015).

53. Knapska, E. \& Kaczmarek, L. A gene for neuronal plasticity in the mammalian brain: Zif268/Egr-1/NGFI-A/Krox-24/TIS8/ZENK? Progress in neurobiology 74, 183-211, https://doi.org/10.1016/j.pneurobio.2004.05.007 (2004).

54. Zetterstrom, R. H. et al. Dopamine neuron agenesis in Nurr1-deficient mice. Science 276, 248-250 (1997).

55. Wagner, J. et al. Induction of a midbrain dopaminergic phenotype in Nurr1-overexpressing neural stem cells by type 1 astrocytes. Nature biotechnology 17, 653-659, https://doi.org/10.1038/10862 (1999).

56. Shim, J. W. et al. Generation of functional dopamine neurons from neural precursor cells isolated from the subventricular zone and white matter of the adult rat brain using Nurr1 overexpression. Stem cells 25, 1252-1262, https://doi.org/10.1634/ stemcells.2006-0274 (2007).

57. Ponnio, T. \& Conneely, O. M. nor-1 regulates hippocampal axon guidance, pyramidal cell survival, and seizure susceptibility. Molecular and cellular biology 24, 9070-9078, https://doi.org/10.1128/MCB.24.20.9070-9078.2004 (2004).

58. Ohkura, N., Hijikuro, M. \& Miki, K. Antisense oligonucleotide to NOR-1, a novel orphan nuclear receptor, induces migration and neurite extension of cultured forebrain cells. Brain research. Molecular brain research 35, 309-313 (1996).

59. Nomiyama, T. et al. The NR4A orphan nuclear receptor NOR1 is induced by platelet-derived growth factor and mediates vascular smooth muscle cell proliferation. The Journal of biological chemistry 281, 33467-33476, https://doi.org/10.1074/jbc.M603436200 (2006).

60. Maruyama, K. et al. Retinoic acids differentially regulate NOR-1 and its closely related orphan nuclear receptor genes in breast cancer cell line MCF-7. Biochemical and biophysical research communications 231, 417-420, https://doi.org/10.1006/bbrc. 1997.6122 (1997).

61. Lam, B. Y. et al. Inverse regulation of plasticity-related immediate early genes by calcineurin in hippocampal neurons. The Journal of biological chemistry 284, 12562-12571, https://doi.org/10.1074/jbc.M901121200 (2009).

62. Sudhof, T. C. The synaptic vesicle cycle. Annual review of neuroscience 27, 509-547, https://doi.org/10.1146/annurev. neuro.26.041002.131412 (2004).

63. Hilfiker, S. et al. Synapsins as regulators of neurotransmitter release. Philosophical transactions of the Royal Society of London. Series B, Biological sciences 354, 269-279, https://doi.org/10.1098/rstb.1999.0378 (1999).

64. Turner, K. M., Burgoyne, R. D. \& Morgan, A. Protein phosphorylation and the regulation of synaptic membrane traffic. Trends in neurosciences 22, 459-464 (1999).

65. Fiumara, F. et al. Phosphorylation by cAMP-dependent protein kinase is essential for synapsin-induced enhancement of neurotransmitter release in invertebrate neurons. Journal of cell science 117, 5145-5154, https://doi.org/10.1242/jcs.01388 (2004).

66. Das, K. P., Freudenrich, T. M. \& Mundy, W. R. Assessment of PC12 cell differentiation and neurite growth: a comparison of morphological and neurochemical measures. Neurotoxicology and teratology 26, 397-406, https://doi.org/10.1016/j.ntt.2004.02.006 (2004).

67. Kao, H. T. et al. A protein kinase A-dependent molecular switch in synapsins regulates neurite outgrowth. Nature neuroscience 5 , 431-437, https://doi.org/10.1038/nn840 (2002).

68. Lee, Y. Y. et al. Bcl-2 Overexpression Induces Neurite Outgrowth via the Bmp4/Tbx3/NeuroD1 Cascade in H19-7 Cells. Cell Mol Neurobiol 40, 153-166, https://doi.org/10.1007/s10571-019-00732-1 (2020).

69. Maddika, S. et al. Cancer-specific toxicity of apoptin is independent of death receptors but involves the loss of mitochondrial membrane potential and the release of mitochondrial cell-death mediators by a Nur77-dependent pathway. Journal of cell science 118, 4485-4493, https://doi.org/10.1242/jcs.02580 (2005).

70. Yang, H., Zhan, Q. \& Wan, Y. J. Enrichment of Nur77 mediated by retinoic acid receptor beta leads to apoptosis of human hepatocellular carcinoma cells induced by fenretinide and histone deacetylase inhibitors. Hepatology 53, 865-874, https://doi. org/10.1002/hep.24101 (2011).

71. Damodaran, T. V., Gupta, R. P., Attia, M. K. \& Abou-Donia, M. B. DFP initiated early alterations of PKA/p-CREB pathway and differential persistence of beta-tubulin subtypes in the CNS of hens contributes to OPIDN. Toxicol Appl Pharmacol 240, 132-142, https://doi.org/10.1016/j.taap.2009.07.035 (2009).

72. Martin, L. J., Boucher, N., El-Asmar, B. \& Tremblay, J. J. cAMP-induced expression of the orphan nuclear receptor Nur77 in MA-10 Leydig cells involves a CaMKI pathway. J Androl 30, 134-145, https://doi.org/10.2164/jandrol.108.006387 (2009).

73. Shimoke, K. et al. NGF-induced phosphatidylinositol 3-kinase signaling pathway prevents thapsigargin-triggered ER stressmediated apoptosis in PC12 cells. Neuroscience letters 389, 124-128, https://doi.org/10.1016/j.neulet.2005.07.030 (2005). 


\section{Acknowledgements}

The authors would like to thank Dr. Yasuo Nagaoka for technical assistance with the experiments. We are grateful to Takuma Tomioka, Kazaho Tsumura and Erika Shimayama for collaboration in the early stages of this work. We also thank Dr. Toshihiko Ikeuchi for many years of advice. This work was supported, in part, by grants-in-aid for scientific research from MEXT (Ministry of Education, Culture, Sports, Science and Technology of Japan), SENRYAKU (2013-2018) and KAKENHI (16K00626).

\section{Author contributions}

Experiment procedure: H.M., R.Y., R.T., K.Y., D.I., Y.F. and F.H.; Data evaluation: H.M. and K.S.; Manuscript writing (including Figures): H.M. and K.S.

\section{Competing interests}

The authors declare no competing interests.

\section{Additional information}

Supplementary information is available for this paper at https://doi.org/10.1038/s41598-020-62968-y.

Correspondence and requests for materials should be addressed to K.S.

Reprints and permissions information is available at www.nature.com/reprints.

Publisher's note Springer Nature remains neutral with regard to jurisdictional claims in published maps and institutional affiliations.

Open Access This article is licensed under a Creative Commons Attribution 4.0 International License, which permits use, sharing, adaptation, distribution and reproduction in any medium or format, as long as you give appropriate credit to the original author(s) and the source, provide a link to the Creative Commons license, and indicate if changes were made. The images or other third party material in this article are included in the article's Creative Commons license, unless indicated otherwise in a credit line to the material. If material is not included in the article's Creative Commons license and your intended use is not permitted by statutory regulation or exceeds the permitted use, you will need to obtain permission directly from the copyright holder. To view a copy of this license, visit http://creativecommons.org/licenses/by/4.0/.

(c) The Author(s) 2020 